American Journal of Applied Sciences 5 (6): 736-741, 2007

ISSN 1546-9239

(C) 2007 Science Publications

\title{
Characterization of Boron Carbonitride (BCN) Thin Films Deposited by Radiofrequency and Microwave Plasma Enhanced Chemical Vapor Deposition
}

\author{
${ }^{1}$ M.A. Mannan, ${ }^{1}$ M. Nagano, ${ }^{1}$ K. Shigezumi, ${ }^{2}$ T. Kida, ${ }^{3}$ N. Hirao and ${ }^{3}$ Y. Baba \\ ${ }^{1}$ Department of Chemistry and Applied Chemistry, Faculty of Science and Engineering, \\ Saga University, 1 Honjo, Saga, 840-8502, Japan \\ ${ }^{2}$ Department of Energy and Material Sciences, Kyushu University, \\ Kasuga-Shi, Fukuoka, 816-8580, Japan \\ ${ }^{3}$ Synchrotron Radiation Research Unit, Quantum Beam Science Directorate, \\ Japan Atomic Energy Agency, Tokai-Mura, Ibaraki, 319-1195, Japan
}

\begin{abstract}
Boron carbonitride (BCN) thin films with a thickness of $\sim 4 \mu \mathrm{m}$ were synthesized on $\mathrm{Si}(100)$ substrate by radiofrequency and microwave plasma enhanced chemical vapor deposition using trimethylamine borane $\left.\left[\left(\mathrm{CH}_{3}\right)_{3} \mathrm{~N} . \mathrm{BH}_{3}\right)\right]$ as a molecular precursor. The microstructures of the films were evaluated using field emission scanning electron microscopy (FE-SEM) and X-ray diffractometry (XRD). Fourier transform infrared spectroscopy (FT-IR) and X-ray photoelectron spectroscopy (XPS) were used to analyze the chemical bonding state and composition of the films. It has been observed that the films were adhered well to the silicon substrate even after being broken mechanically. XRD and FESEM results showed that the films were $x$-ray amorphous, rough surface with inhomogeneous microstructure. The micro hardness was measured by nano-indentation tester and was found to be approximately 2 7 GPa. FT-IR suggested the formation of the hexagonal boron carbonitride (h-BCN) phase in the films. Broadening of the XPS peaks revealed that $\mathrm{B}, \mathrm{C}$ and $\mathrm{N}$ atoms have different chemical bonds such as B-N, B-C and C-N. The impurity oxygen was detected (13 15 at.\%) as B-O and/or N-O.
\end{abstract}

Key words: RF/MW plasma CVD, FT-IR, XPS, trimethylamine borane, boron carbonitride thin film

\section{INTRODUCTION}

Recently, the boron carbonitride (BCN) films have attracted much attention due to their potential applications to electronic, optoelectronic and luminescent devices. The cubic boron carbonitride (c-BCN) compound is expected to be a hard material superior to diamond ${ }^{[1]}$ and could be used for wear resisted coatings, insulator and heat sink. The hexagonal compound (h-BCN) is attractive in the applications to electronic and luminescent devices due to its semi-conducting properties with variable energy band-gap ${ }^{[2]}$. Diamond possesses extreme hardness but one disadvantage is its reaction with ferrous materials at high temperature ${ }^{[3]}$. The cubic boron nitride $(\mathrm{c}-\mathrm{BN})$ is stable at high temperature but high internal stress in c$\mathrm{BN}$ films is a major limitation for the applications of the c-BN films ${ }^{[4]}$. The $\mathrm{BCN}$ compounds are regarded as a promising candidate for the hardest materials and are expected to overcome these difficulties and possess properties between those of diamond and c-BN. Much efforts has been devoted for the synthesis of BCN films with various atomic compositions such as chemical vapor deposition ${ }^{[5,6]}$, radio frequency magnetron sputtering $^{[7,8]}$, pulsed laser ablation ${ }^{[9,10]}$, ion beam sputtering ${ }^{[11]}$ etc. However, the synthesis of a single phase of the cubic or hexagonal BCN compounds is still a great challenge.

In this study, RF and MW plasma enhanced chemical vapor deposition were used to deposit $\mathrm{BCN}$ films from trimethylamine borane (TMAB) as a precursor. The chemical composition, bonding states and characteristics of the films were investigated by various instrumental methods.

\section{MATERIALS AND METHODS}

BCN films were synthesized on Si (100) substrate by $\mathrm{RF}$ and MW plasma enhanced chemical vapor deposition (RF/MW-PECVD). The RF-PECVD system is schematically shown in Fig. 1. The reaction chamber is a quartz tube of $120 \mathrm{~cm}$ in length and $28 \mathrm{~mm}$ inner

Corresponding Author: Md. Abdul Mannan, Department of Chemistry and Applied Chemistry, Faculty of Science and Engineering, Saga University, 1 Honjo, Saga 840-8502, Japan 
Am. J. Applied Sci., 5 (6): 736-741, 2007

Table 1: Details of the reaction condition and the mechanical property of the deposited BCN films

\begin{tabular}{|c|c|c|c|c|c|c|c|c|}
\hline Power & $\begin{array}{l}\text { Sample } \\
\text { No. }\end{array}$ & $\begin{array}{l}\text { RF/MW } \\
\text { power } \\
\text { (W) }\end{array}$ & $\begin{array}{l}\text { Reaction } \\
\text { pressure } \\
\text { (Torr) }\end{array}$ & $\mathrm{T}_{\text {sub }}\left({ }^{\circ} \mathrm{C}\right)$ & $\begin{array}{l}\text { Flow rate of } \\
\text { precursor } \\
(\mathrm{SCCM})\end{array}$ & $\begin{array}{l}\text { Depositi-on } \\
\text { time (Hour) }\end{array}$ & $\begin{array}{l}\text { Thick- ness } \\
(\mu \mathrm{m})\end{array}$ & $\begin{array}{l}\text { Hard-ness } \\
\text { (GPa) }\end{array}$ \\
\hline \multirow[t]{2}{*}{$\overline{\mathrm{RF}}$} & 1 & 400 & 2.0 & 300 & 1.89 & 2 & 4.5 & 6.7 \\
\hline & 2 & 400 & 2.0 & 600 & 1.28 & 2 & 4.2 & 1.9 \\
\hline \multirow[t]{2}{*}{ MW } & 3 & 400 & 15 & 840 & 1.71 & 2 & 4.9 & 5.2 \\
\hline & 4 & 300 & 35 & 850 & 2.23 & 2 & 3.3 & 2.3 \\
\hline
\end{tabular}

$\mathrm{T}_{\text {sub }}=$ Substrate temperature

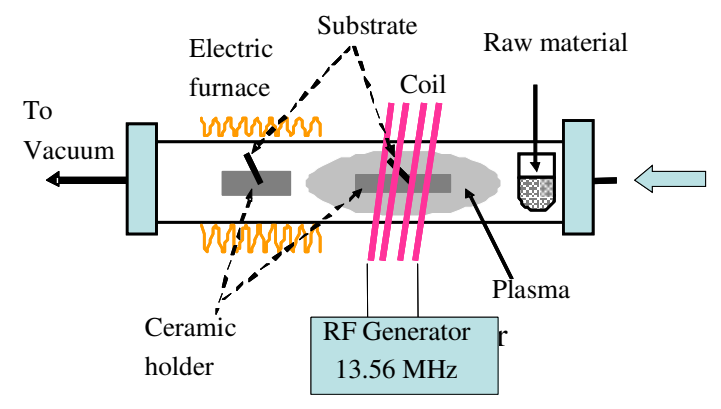

Fig. 1: Schematic representation of RF-plasma CVD for the deposition of $\mathrm{BCN}$ films

diameter.

The RF generator of $1 \mathrm{~kW}, 13.56 \mathrm{MHz}$ was used as the plasma generator which was coupled with a turn copper coil and installed around the reaction tube.

An electric furnace composed of $\mathrm{Ni}-\mathrm{Cr}$ heating element was set $20 \mathrm{~cm}$ apart from the copper coil. The reaction system was evacuated by using a combination of a rotary and an oil diffusion pumps. The Si substrate $\left(1 \times 1 \mathrm{~cm}^{2}\right)$ was cleaned with acetone by ultrasonic cleaner for about 10 minutes followed by HF (50\%) soaking for 30s to remove the surface oxides (if any). Then it was rinsed with acetone and finally dried with a stream of nitrogen gas. After cleaning the substrate, it was set on a ceramic holder and transferred immediately into the reaction chamber and was heated either by the electric furnace or the plasma. An allocated amount of the precursor material (Trimethylamine borane (TMAB); 97\%, Wako Pure Chemical Industries, LTD.) was put in a crucible and placed in the reaction tube $\sim 15 \mathrm{~cm}$ apart from the plasma. The flow rate of the raw material was calculated from the weight loss during the reaction period. An optical pyrometer (Model IR-U, CHINO) or a Pt/Pt-13\% Rh thermocouple was used to measure the substrate temperature. Pure hydrogen (99.99\%, Iwatani, Co. Japan) supplied from a cylinder was used as carrier gas and the flow rate was monitored by using a mass flow controller (MKS, Type 122A). The deposition was performed under different reaction conditions summarized in Table 1.
The detail of the MW-PECVD system using microwave $(2.45 \mathrm{GHz})$ plasma has been reported elsewhere $^{[12]}$.

The chemical bonding states and compositions of the as-deposited BCN films were studied by FT-IR (Spectrum 2000, Perkin Elmer) and XPS (VG, CLAM2). The FT-IR spectra were recorded after subtracting the background spectra of the Si substrate.

The ex situ XPS measurements were performed using Linearly Polarized Synchrotron Radiation at the Beam Line 27A of the Photon Factory in the High Energy Acceleration Research Organization (KEK-PF), Tsukuba, Japan. The XPS spectra were calibrated by measuring the binding energy of $\mathrm{Ag} 3 \mathrm{~d}_{5 / 2}$ line at $368.4 \mathrm{eV}$ with respect to the Fermi level. The crystallinity was investigated by XRD (Rigaku diffractometer). The XRD spectra of the films with $\mathrm{CuK}_{\square}$ radiation were recorded by the diffractometer using a grazing incidence mode (incidence angle $2^{\circ}$, $30 \mathrm{kV}, 20 \mathrm{~mA}$ ). The layer thicknesses of the films were measured from the cross-section FE-SEM images (JSM-6700 FSS, JEOL) of the films. The micro hardness was estimated from the loading-unloading curves obtained from the nano-indentation tests (ENT1100, Elionix). Indentations were made with a maximum load of $10 \mathrm{mN}$ and the average hardness values were determined from 10 indentations for each of the samples. The thickness and micro hardness values are incorporated in Table 1.

\section{RESULTS AND DISCUSSION}

XRD analyses: The grazing incidence XRD (incidence angle $2^{\circ}$ ) spectra were recorded in a wide scanning range of $2 \theta=20-80^{\circ}$. However, no diffraction peaks were identified for all the films. The absences of the diffraction peaks suggested that the deposited films were X-ray amorphous.

Microstructure analyses: The typical high resolution FE-SEM morphologies of the as-deposited BCN films are shown in Fig. 2. The films revealed inhomogeneous microstructure and the surface roughness was high for all the samples. 

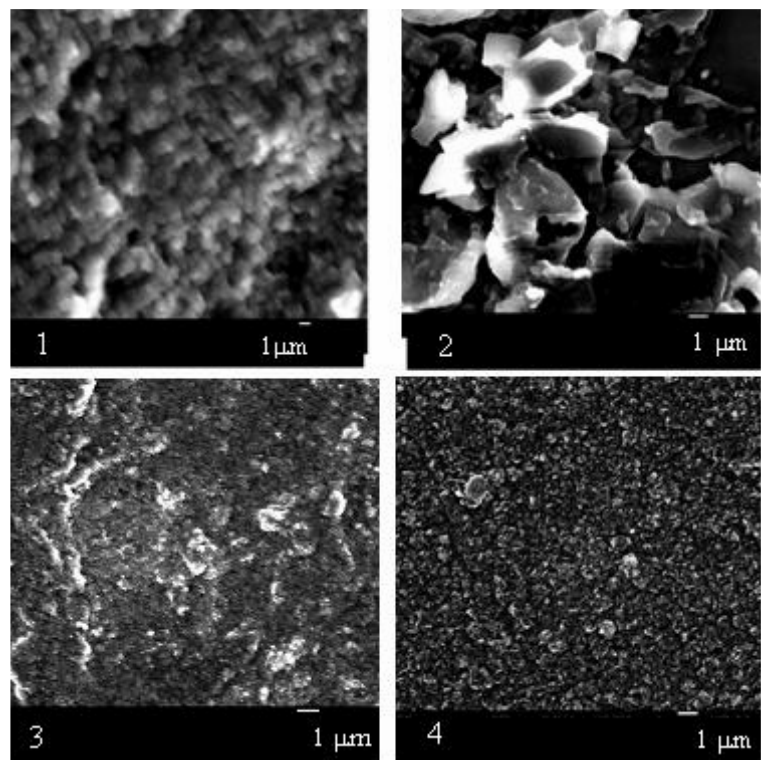

Fig. 2: Surface FE-SEM morphologies of the deposited BCN films

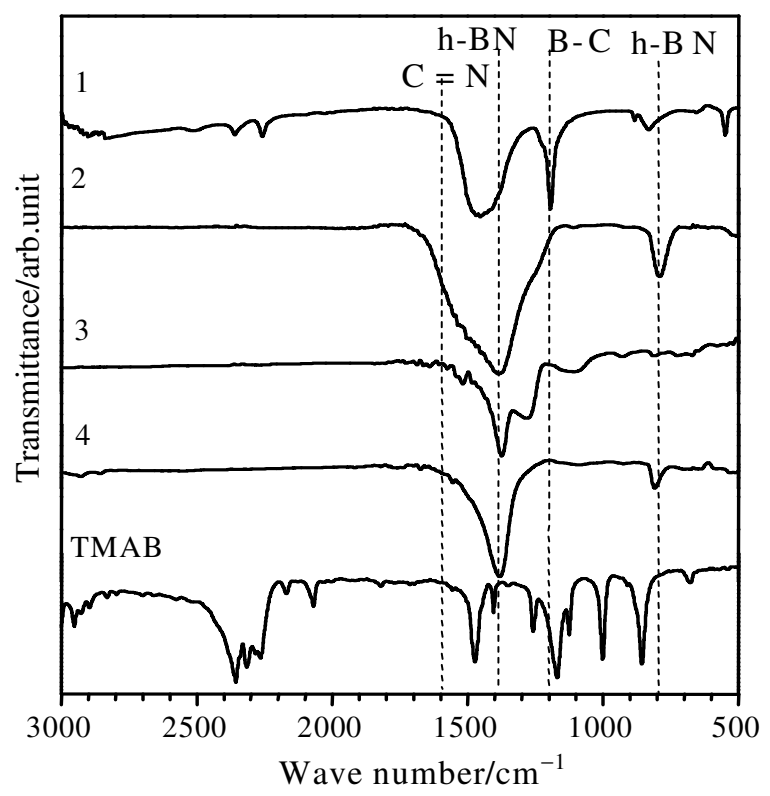

Fig. 3: FT-IR spectra of four typical samples. Samples 1 and 2 were synthesized by RF plasma while samples 3 and 4 by MW plasma CVD. The bottom cure shows the spectrum of the raw material (TMAB) for comparison

FT-IR analyses: The FT-IR transmission spectra of the four typical samples are shown in Fig. 3. The IR spectrum of TMAB is also shown at the bottom for

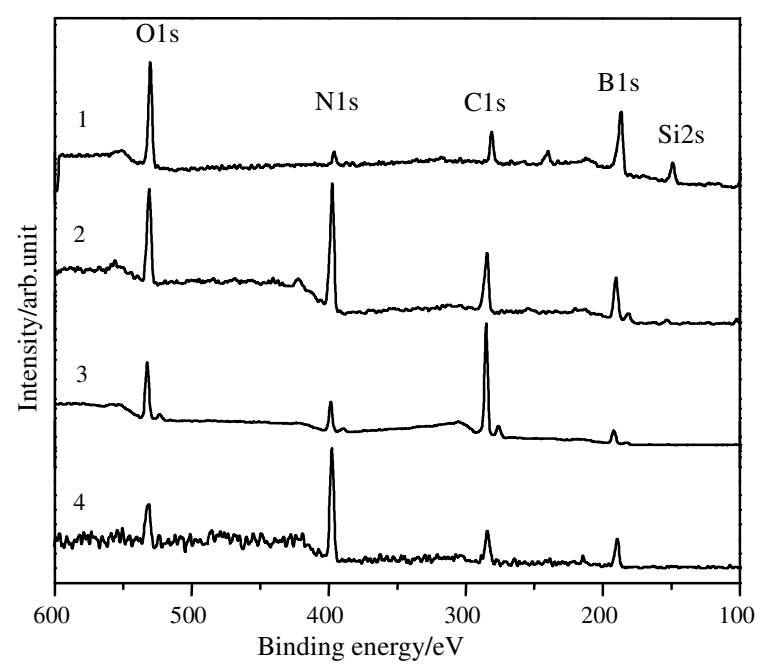

Fig. 4: XPS wide scan spectra of the typical samples shown in Fig. 3

comparison. Samples 1 and 2 were synthesized by RFPECVD while the samples 3 and 4 by MW-PECVD.

Sample 1 was deposited in the electric furnace while the other samples were deposited in the plasma.

Compared the spectra of the raw material to that of the products, the raw material was almost decomposed into BCN compound. For all the samples, two bands are observed at $\sim 1400$ and $\sim 800 \mathrm{~cm}^{-1}$, although the band at $800 \mathrm{~cm}^{-1}$ is very weak for samples 1 and 3 . The h-BN has these characteristic bands at 1400 and $800 \mathrm{~cm}^{-1[13]}$. Broadening of the bands for our present samples indicates incorporation of $\mathrm{C}$ into the h-BN to form the BCN compounds ${ }^{[14]}$. In sample 1 , there is a sharp band at $1200 \mathrm{~cm}^{-1}$. It might be ascribed to a carbon rich B-C bond $^{[15]}$. However, we could not found any bands near $1200 \mathrm{~cm}^{-1}$ for other samples. A sharp band at 1200 $\mathrm{cm}^{-1}$ is also found in the spectrum of TMAB which does not have B-C bond. Therefore, further investigations are needed to assign the band at 1200 $\mathrm{cm}^{-1}$. The $\mathrm{C}-\mathrm{N}, \mathrm{C}=\mathrm{N}$ and $\mathrm{C} \equiv \mathrm{N}$ bonds usually appear approximately at $1300 \mathrm{~cm}^{-1}, 1600 \mathrm{~cm}^{-1}$ and $2170 \mathrm{~cm}^{-1}$ respectively ${ }^{[16]}$. Therefore, broad band from $1300 \sim 1600 \mathrm{~cm}^{-1}$ suggests the formation of the C-N and/or $\mathrm{C}=\mathrm{N}$ bonds whilst the $\mathrm{C} \equiv \mathrm{N}$ bonds are not confirmed. The prominent absorption band corresponding to $\mathrm{C}-\mathrm{H}$ bonds are usually observed between $2800 \sim 3000 \mathrm{~cm}^{-1[17]}$, the $\mathrm{O}-\mathrm{H}$ bonds at $\sim 3600$ $\mathrm{cm}^{-1}$ and the N-H bonds at $3200 \sim 3370 \mathrm{~cm}^{-1[7]}$. The presences of the absorption bands ascribed to the hydrogenated groups such as $\mathrm{C}-\mathrm{H}, \mathrm{N}-\mathrm{H}$ or $\mathrm{O}-\mathrm{H}$ are not clearly confirmed in the spectra.

XPS analyses: Figure 4 shows XPS wide scan spectra of the typical samples. The spectra showed the B1s, 

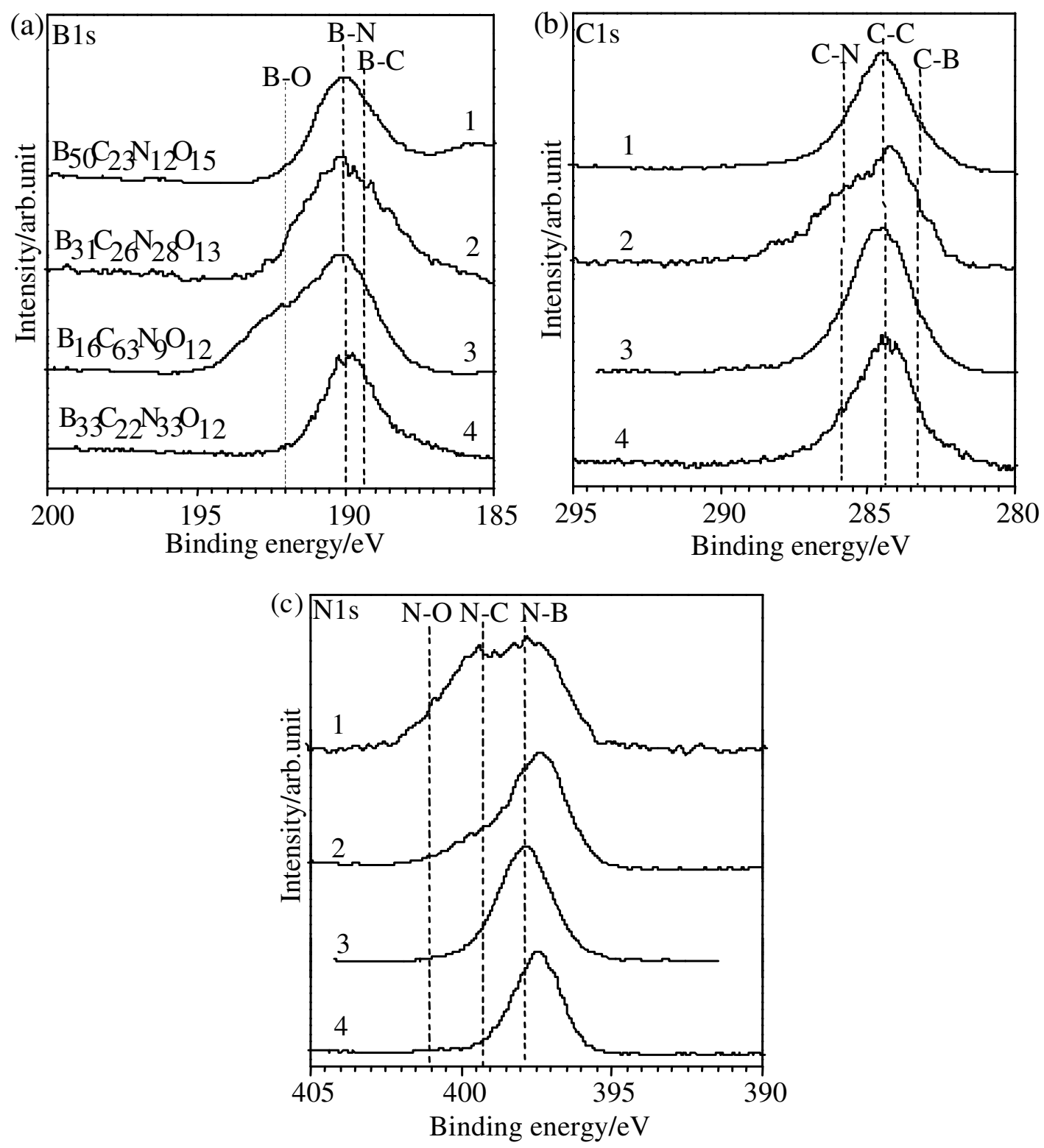

Fig. 5: XPS spectra of B1s, C1s and N1s of the deposited samples together with their compositions shown in Fig. 3

$\mathrm{C} 1 \mathrm{~s}$ and N1s peaks together with the impurity O1s peak. The compositions of the films were estimated from the integral area of the XPS peaks to be: $\mathrm{B}_{50} \mathrm{C}_{23} \mathrm{~N}_{12} \mathrm{O}_{15}$ (sample 1), $\mathrm{B}_{31} \mathrm{C}_{26} \mathrm{~N}_{28} \mathrm{O}_{13}$ (sample 2), $\mathrm{B}_{16} \mathrm{C}_{63} \mathrm{~N}_{9} \mathrm{O}_{12}$ (sample 3) and $\mathrm{B}_{33} \mathrm{C}_{22} \mathrm{~N}_{33} \mathrm{O}_{12}$ (sample 4) respectively. The impurity oxygen probably comes from the residual water or oxygen adsorbed in the reaction tube during the deposition and also may be due to the surface contamination after deposition. The silicon peak detected in sample 1 may be ascribed to the substrate $\mathrm{Si}$ because of the high roughness and heterogeneity of the film surface.
Figure 5 illustrates the detail spectra of $\mathrm{B} 1 \mathrm{~s}, \mathrm{C} 1 \mathrm{~s}$ and N1s. The full widths at half maximum $(F W H M=\sim 2.5 \mathrm{eV})$ of $\mathrm{B} 1 \mathrm{~s}$ peaks for the deposited samples are larger than that of $h-B N$ $(\text { FWHM }=1.7 \mathrm{eV})^{[18]}$. Broadening of the spectra suggests that $\mathrm{B}$ atoms have not only the $\mathrm{BN}_{3}$ configurations but also other $\mathrm{BN}_{3-\mathrm{x}} \mathrm{C}_{\mathrm{x}}$ configurations $(\mathrm{x}=1,2)$. The $\mathrm{B} 1 \mathrm{~s}$ peak of $\mathrm{h}-\mathrm{BN}$ is reported at 190.2 $\mathrm{eV}^{[19]}$ while the $\mathrm{B} 1 \mathrm{~s}$ peak positions of the B-C-N materials are fluctuated in the ranges from 188 to 191 $\mathrm{eV}^{[20,21]}$. This may be due to the variation of configurations in the B-C-N films. Therefore, the B1s 
binding energy centered at $190.0 \mathrm{eV}$ in Fig. 5a implies the formation of the hexagonal boron carbonitride (h-BCN). The hexagonal phase is also supported by the FT-IR spectra. The broadening of peak to the lower energy side indicates the contribution of B-C bonding because the

peak energy of $\mathrm{BC}_{3.4}$ and $\mathrm{B}_{4} \mathrm{C}$ have been found to be 189.4 and $188.4 \mathrm{eV}$ respectively ${ }^{[22]}$. The $\mathrm{B} 1 \mathrm{~s}$ peak in h- $\mathrm{BN}_{3-\mathrm{x}} \mathrm{C}_{\mathrm{x}}$ should have the binding energy between $\mathrm{BC}_{3}$ and $\mathrm{BN}_{3}$ configurations due to the electronegativity differences among the $\mathrm{C}$ and $\mathrm{N}$ atoms ${ }^{[14]}$. The proposed configuration $\left(\mathrm{h}-\mathrm{BN}_{3-\mathrm{x}} \mathrm{C}_{\mathrm{x}}\right)$ to the lower energy corresponds to the $\mathrm{B}$ atom bonded in graphite like stoichiometric $\mathrm{BCN}_{2}$ and/or more probably in a $\mathrm{BC}_{2} \mathrm{~N}$ compounds as there are relatively more atomic concentration of carbon than nitrogen. The broadening of the $\mathrm{B} 1 \mathrm{~s}$ peak to higher binding energy region may be due to B-O bond because its binding energy is reported in the range of $(192-193 \mathrm{eV})^{[23]}$.

In Fig. 5b, the binding energy of $\mathrm{C} 1 \mathrm{~s}$ centered at $284.4 \mathrm{eV}$ could be assigned to $\mathrm{C}-\mathrm{C}$ bonding ${ }^{[7,10]}$. Linss et al. reported that the $\mathrm{C} 1 \mathrm{~s}$ energy greater than $285 \mathrm{eV}$ is due to $\mathrm{C}$ atom bonded to more electronegative $\mathrm{N}$ atom ${ }^{[14]}$. The $\mathrm{C} 1 \mathrm{~s}$ energies for $\mathrm{BC}_{3.4}$ and $\mathrm{B}_{4} \mathrm{C}$ have been reported to be 284.3 and $283.0 \mathrm{eV}$ respectively ${ }^{[24]}$. Therefore, the broadening of the spectra to the higher energy side suggests the formation of $\mathrm{C}-\mathrm{N}$ bonding such as $\mathrm{CC}_{3-\mathrm{x}} \mathrm{N}_{\mathrm{x}}$ whilst the broadening to the lower energy side suggest the $\mathrm{C}-\mathrm{B}$ bonding such as $\mathrm{CC}_{3-\mathrm{x}} \mathrm{B}_{\mathrm{x}}$. The configurations $\mathrm{CC}_{3-\mathrm{x}} \mathrm{N}_{\mathrm{x}}$ and $\mathrm{CC}_{3-\mathrm{x}} \mathrm{B}_{\mathrm{x}}$ might be corresponding to the graphitic carbon bonded to $\mathrm{N}$ and $\mathrm{B}$ respectively. These results confirm that $\mathrm{C}$ atoms are mostly bonded to $\mathrm{C}$ although there are $\mathrm{C}$ atoms bonded to $\mathrm{B}$ and / or N. However, the broadening to the higher energy side due to $\mathrm{C}-\mathrm{O}$ bonding reported at $288.5 \mathrm{eV}$ is not obvious ${ }^{[10]}$.

The XPS spectra for N1s are shown in Fig. 5c. The $\mathrm{N} 1 \mathrm{~s}$ peak energy centered at $398.0 \mathrm{eV}$ for samples 1 and 3 is in accordance with the B-N bonding in $h-$ $\mathrm{BN}^{[23]}$. The peak is shifted to the lower energy side for samples 2 and 4 . It might be due to the higher concentration of $\mathrm{N}$ atoms in these samples than that of the samples 1 and 3. The peak at $399.2 \mathrm{eV}$ for samples 1 and 2 may be assigned to the N-C bonding ${ }^{[20]}$. Broadening of the peak to the higher binding energy for sample 1 may be due to $\mathrm{N}-\mathrm{O}$ bonding reported at 401 $\mathrm{eV}^{[23]}$. The N1s spectra are not supportive to find out more information regarding the bonding states because the binding energy range for $\mathrm{N}$ atoms bonding to $\mathrm{B}$ and $\mathrm{C}$ is relatively small ${ }^{[14]}$ and the interpretation, therefore, is very ambiguous.

The XPS results indicated that the B-N, B-C and $\mathrm{C}-\mathrm{N}$ bondings are formed in the deposited $\mathrm{BCN}$ films.
Unfortunately contamination with oxygen in the form of the B-O and/or N-O bonding was met evitable. As there are different atomic environments at $\mathrm{B}, \mathrm{C}$ and $\mathrm{N}$ sites further studies are needed to clarify the configuration at the specific elemental site and to distinguish BCN compound from the mixture of boron nitride, graphitic carbon and /or carbon nitride.

\section{CONCLUSION}

Radiofrequency and microwave plasma CVD were used to synthesis of $\mathrm{BCN}$ films using trimethylamine borane as a precursor at different reaction conditions. The films were amorphous with inhomogeneous microstructure confirmed by XRD and FE-SEM. XPS and FT-IR suggested that the films were consisted of a variety of bonds between $\mathrm{B}, \mathrm{C}$ and $\mathrm{N}$ atoms such as B-N, B-C and C-N. Oxygen was inevitably incorporated as a contaminant. The boron atoms are mainly bonded to nitrogen to form the $\mathrm{sp}^{2} \mathrm{~B}-\mathrm{N}$ bonding similar to that in the h-BN $\left(\mathrm{BN}_{3}\right.$ configuration) while the formation of other configurations such as $\mathrm{BCN}_{2}$ and/or $\mathrm{BC}_{2} \mathrm{~N}$ suggested by the broadening of the XPS spectra. Carbon atoms mostly formed the graphitic $\mathrm{sp}^{2}$ C-C bonding together with the small component of C-B and $\mathrm{C}-\mathrm{N}$ bondings. The nitrogen atoms are mainly bonded to boron to form the N-B bonding although the $\mathrm{N}-\mathrm{C}$ bonding is clearly appeared in the films. As there are different atomic environments at $\mathrm{B}, \mathrm{C}$ and $\mathrm{N}$ sites, further studies are needed to clarify the local atomic configuration to clearly distinguish between the $\mathrm{BCN}$ compounds and the mixture of boron nitride, graphitic carbon and /or carbon nitride.

\section{ACKNOWLEDGEMENTS}

The authors would like to thanks the staff of the KEK-PF for supporting the XPS measurements. The XPS measurements were performed under the approval of Photon Factory Program Advisory Committee (Proposal No. 2006G312). The authors also express their thanks to Mr. A. Shiraishi of Saga Ceramic Research Laboratory for the SEM measurements.

\section{REFERENCES}

1. Tateyama, Y., T. Ogitsi, K. Kusakabe and S. Tsuneyuki, 1997. Proposed synthesis path for heterodiamond $\quad \mathrm{BC}_{2} \mathrm{~N}$. Phys. Rev. B., 55: 10161-10164.

2. Kawaguchi, M., 1997. B/C/N materials based on the graphite network. Adv. Mater., 9: 615-625. 
3. Hegemann, D., R. Riedel and C. Oehr, 1999. Influence of single-source precursors on PACVDderived boron carbonitride thin films. Thin Solid Films, 339: 154-159.

4. Hahn, J., M. Friedrich, R. Pintaske, M. Schaller, N. Kahl, D.R.T. Zahn and F. Richter, 1996. Cubic boron nitride films by d.c. and r.f. magnetron sputtering: layer characterization and process diagnostics. Diamond Relat. Mater., 5: 1103-1112.

5. Yuki, T., S. Umeda and T. Sugino, 2004. Electrical and optical characteristics of boron carbon nitride films synthesized by plasma-assisted chemical vapor deposition. Diamond Relat. Mater., 13: 1130-1134.

6. Mineo, M. and T. Satoh, 2001. Study of BCN compounds prepared by the chemical vapor deposition with dimethylamineborane. J. Mat. Sci., 36: 3925-3931.

7. Essafti, A., E. Ech-chamikh and J.L.G. Fierro, 2005. Structural and chemical analysis of amorphous B-N-C thin films deposited by RF sputtering. Diamond Relat. Mater., 14: 1663- 1668.

8. Liu, L., Y. Wang, K. Feng, Y. Li, W. Li, C. Zhao and Y. Zhao, 2006. Preparation of boron carbon nitride thin films by radio frequency magnetron sputtering. Appl. Surf. Sci., 252: 4185-4189.

9. Zhang, C.Y., X.L. Zhong, J.B. Wang and G.W. Yang, 2003. Room-temperature growth of cubic nitride boron film by RF plasma enhanced pulsed laser deposition. Chem. Phys. Lett., 370: 522-527.

10. Pan, W.J., J. Sun, H. Ling, N. Xu, Z. F. Ying and J. D. Wu, 2003. Preparation of thin films of carbon-based compounds. Appl. Surf. Sci., 218: 297-304.

11. Morant, C., P. Prieto, J. Bareno, J.M. Sanz and E. Elizalde, 2006. Hard $\mathrm{BC}_{\mathrm{x}} \mathrm{N}_{\mathrm{y}}$ thin films grown by dual ion beam sputtering. Thin Solid films, 515: 207-211.

12. Uddin, M.N., O. A. Fouad, M. Yamzato and M. Nagano, 2005. Deposition and characterization of carbon nitride films from hexamethylenetetramine $/ \mathrm{N}_{2}$ by microwave plasmaenhanced chemical vapor deposition. Appl. Surf. Sci., 240: 120-130.

13. Hasegawa, T., K. Yamamoto and Y. Kakudate, 2003. Influence of raw gases on B-C-N films prepared by electron beam excited plasma CVD. Diamond Relat. Mater., 12: 1045-1048.
14. Linss, V., S.E. Rodil, P. Reinke, M.G. Garnier, P. Oelhafen, U. Kreissig and F. Richter, 2004. Bonding characteristics of DC magnetron sputtered B-C-N thin films investigated by Fouriertransformed infrared spectroscopy and X-ray photoelectron spectroscopy. Thin Solid Films, 467: 76-87.

15. Gago, R., I. Jimenez, F. Agullo-Rueda, J.M. Albella, L.Zs. Czigany and J. Hultman, 2002. Transition from amorphous boron carbide to hexagonal boron carbon nitride thin films induced by nitrogen ion assistance. Appl. Phys., 92: 5177-5182.

16. Caretti, I., I. Jimenez and J.M. Albella, 2003. BCN films with controlled composition obtained by the interaction between molecular beams of $\mathrm{B}$ and $\mathrm{C}$ with nitrogen ion beams. Diamond Relat. Mater., 12: 1079-1083.

17. Tomasella, E., C. Meunier and S. Mikhailov, 2001. a-C:H thin films deposited by radio-frequency plasma: influence of gas composition on structure, optical properties and stress levels. Surf. Coat. Technol., 141: 286-296.

18. Uddin, M.N., I. Shimoyama, Y. Baba, T. Sekiguchi, K.G. Nath and M. Nagano, 2005. B-C-N hybrid synthesis by high-temperature ion implantation. Appl. Surf. Sci., 241: 246-249.

19. Chiang, C.I., O. Meyer and R.M.C. da Silva, 1996. The modification of mechanical properties and adhesion of boron carbide sputtered films by ion implantation. Nucl. Instrum. Methods B., 117: 408-414.

20. Perrone, A., A.P. Caricato, A. Luches, M. Dinescu, C. Ghica, V. Sandu and A. Andrei, 1998. Boron carbonitride films deposited by pulsed laser ablation. Appl. Surf. Sci., 133: 239- 242.

21. Dinescu, M., A. Perrone, A.P. Caricato, L. Mirenghi, C. Gerardi, C. Ghica and L. Frunza, 1998. Boron carbon nitride films deposited by sequential pulses laser deposition. Appl. Surf. Sci., 127-129: 692-696.

22. Polo, M.C., E. Martinez, J. Esteve and J.L. Andujar, 1998. Preparation of B-C-N thin films by r.f. plasma assisted CVD. Diamond Relat. Mater., 7: 376-379.

23. Laidani, N., M. Anderle, R. Canteri, L. Elia, A. Luches, M. Martino, V. Micheli and G. Speranza, 2000. Strucural and compositional study of B-C-N films produced by laser ablation of $\mathrm{B}_{4} \mathrm{C}$ targets in $\mathrm{N}_{2}$ atmosphere. Appl. Surf. Sci., 157: 135-144.

24. Watanabe, M.O., S. Itoh, K. Mizushima and T. Sasaki, 1996. Bonding characterization of $\mathrm{BC}_{2} \mathrm{~N}$ thin films. Appl. Phys. Lett., 68: 2962-2964. 